\title{
Assessment of Hearing Loss in Patients Receiving Chemoradiotherapy in Adjuvant Setting for Head and Neck Malignancy
}

\author{
Vani Krishana Gupta ${ }^{1}$ Mahesh Bhat ${ }^{1}$ Vinay Vaidyanathan Rao ${ }^{1}$ Vishak Surendra ${ }^{1}$ \\ ${ }^{1}$ Department of ENT, Father Muller Medical College, Mangalore, \\ Address for correspondence Vani Krishana Gupta, MBBS, MS, DNB, \\ Karnataka, India \\ Department of ENT, Father Muller Medical College, \\ Kankanady 575002, Mangalore, Karnataka, India \\ (e-mail: vanikrishanagupta@gmail.com).
}

Ann Otol Neurotol:2020;3:16-22

\begin{abstract}
Introduction The aim of the study is to assess the hearing loss in patients who receive chemoradiation (chemoradiotherapy or CTRT) for head and neck malignancies. Materials and Methods Prospective study was conducted in the Department of ENT of a tertiary care center from September 2013 to August 2014. Forty patients suffering from head and neck malignancies (histologically proven) were included in the study. Patients with pre-existing hearing loss were excluded. All patients received radiotherapy dose of 66 to 70 Gy given as 2 Gy/d, 5 d/wk and chemotherapy dose of cisplatin $35 \mathrm{mg} / \mathrm{m}^{2}$ once a week for 6 weeks. Hearing was assessed by pure tone audiometry (PTA) and impedance audiometry conducted at regular intervals. Mcnemars chi-square test was used to compare the impedance and paired $t$-test and Pearson's correlation were used to compare PTA at various stages.

Results Predominantly male patients (28) falling in the age group of 40 to 60 years, suffered from various head and neck cancer, most common being oropharynx (14). Twenty patients developed sensorineural hearing loss (SNHL)-11(55\%) had mild,

Keywords

- chemoradiation

- head and neck malignancies

- two-dimensional radiotherapy

- three-dimensional radiotherapy

- intensity-modulated radiotherapy

- sensorineural hearing loss

- conductive hearing loss seven $(35 \%)$ had moderate, and two $(10 \%)$ had severe grade of SNHL. Majority of these patients, $12(60 \%)$ started developing SNHL mid-therapy, five (25\%) at the completion of therapy and three (15\%) 3 months post-therapy. Hearing loss was found to be more with two-dimensional radiotherapy (2DRT) and three-dimensional radiotherapy (3DRT) than with intensity-modulated radiotherapy (IMRT) as assessed by serial PTA. The average dose of radiation to right and left ears, respectively were 27.10 and $24.66 \mathrm{~Gy}$. The incidence of otitis media with effusion increased during the treatment accounting for the conductive hearing loss irrespective of the modality of radiation used.

Conclusion CTRT causes significant hearing loss in patients suffering from head and neck malignancies leading to further increase in the morbidity. Screening audiological assessment would be helpful to know the pretherapy status of the ear. Using newer modalities like IMRT can reduce hearing loss. Regular audiological screening can catch it at its onset and help in early use of hearing aids.
\end{abstract}

DOI https://doi.org/

$10.1055 / \mathrm{s}-0040-1715289$

ISSN 2581-9607.
Copyright $\odot 2020$ Indian Society of Otology
License terms

() (1) $\ominus \circledast$ 


\section{Introduction}

In India, head and neck cancers account for $30 \%$ of all the cancers. Around 60 to $80 \%$ of patients present with advanced disease as compared with $40 \%$ in developed countries. ${ }^{1}$ Chemoradiotherapy (CTRT) is the most common modality of treatment for advanced head and neck cancers. The temporal bone is invariably present in the irradiated field, though the dose varies. This exposes the cochlea and pharyngeal end of Eustachian tube (ET) to high dose of radiation, resulting in significant changes in the external, middle (in the form of OME), and inner ear in the form of sensorineural hearing loss (SNHL). It is usually a high frequency SNHL that begins either during therapy or up to 6 to 24 months after therapy. It can also progress to complete deafness. The type of radiotherapy (RT) also plays a role in the degree of hearing loss. The widely used chemotherapeutic drug, cisplatin, is also known to cause ototoxicity, thus adding to the SNHL.

This hearing impairment can cause significant disability in these patients especially with bilateral hearing loss. Hence this should be kept in mind during the preradiotherapy counseling and post-radiotherapy follow-up of these patients.

\section{Materials and Methods}

Prospective study was conducted in the Department of ENT at Father Muller Medical College from September 2013 to August 2014. Forty patients (80 ears) diagnosed with head and neck malignancies in advanced state and planned to undergo CTRT in adjuvant setting were selected for the study. Those with pre-existing hearing loss were excluded from the study. Patients received two-dimensional radiotherapy (2DRT)/three-dimensional radiotherapy (3DRT)/intensitymodulated radiotherapy (IMRT) with a daily dose of $2 \mathrm{~Gy}$, 5 days a week, amounting to a total of 66 to $70 \mathrm{~Gy}$. Cisplatin, the chemotherapeutic drug was given at a dose of $35 \mathrm{mg} / \mathrm{m}^{2}$ weekly for 6 weeks. Pure tone audiometry (PTA) was done at four stages: pretherapy, mid therapy, at the completion of therapy, and 3 months post-therapy using Grason Stadler GSI 61 audiometer. An average of hearing threshold at frequencies of $500,1,000,2,000$, and 4,000 was taken. Impedance audiometry was done twice, pretherapy and post-therapy. World Health Organization's gradation of hearing loss was applied. ${ }^{2}$

The results were then subjected to statistical tests. Paired $t$-test was used to compare hearing thresholds from baseline to post-therapy and Pearson's correlation was used to compare hearing thresholds over the course of therapy. Repeated measures ANOVA tests were done to compare hearing loss of the three modalities of RT. Mcnemars chi-square test was used to compare impedance pretherapy and post-therapy.

\section{Results}

Thirty-five (87.5\%) were males while five (12.5\%) were females. They fell in the age range of 33 to 70 years with predominant (28) between 41 and 60 years. Amongst the various subsites of cancer, oropharynx (14) was the most common, followed by tongue (seven), buccal mucosa (seven), larynx (four), hypopharynx (four), and one each in hard palate, gingivobuccal sulcus, floor of mouth, and nasal cavity. Twenty-three (57.5\%) received 2DRT, 11 (27.5\%) received 3DRT, and six (15\%) received IMRT.

Hearing assessment was done by comparing an average of PTA readings of right and left ears over the decided time frame, by comparing hearing loss (in decibel) amongst the three modalities of RT and by comparing impedance audiometry findings over the time frame. Twenty patients (50\%) developed SNHL, amongst them eight suffered from bilateral SNHL. Out of these 20, 11 (55\%) had mild, seven (35\%) had moderate, and two (10\%) had severe grade of SNHL. Majority of these patients, 12 (60\%) started developing SNHL mid-therapy, five $(25 \%)$ at the completion of therapy and three (15\%) 3 months post-therapy.

The average hearing loss in right ear was-pretherapy 18.16 (normal hearing), mid-therapy 22.89 , at the completion of therapy 28.18 , and 3-months post-therapy 30.17 . Hearing loss in the left ear during same time periods was 19.27, 25.3, 29.19, and 31.37 ( - Fig. 1). A progressive increase in hearing loss was noted in both the ears which was statistically significant $(<0.001)$. Hearing loss was compared between 2DRT, 3DRT, and IMRT for both right and left ears (-Figs. 2 and $\mathbf{3}$ ). The mean hearing loss was higher in patients who received 2DRT as compared with those who received 3DRT and IMRT. Correlation of hearing loss and increasing patient age was done (-Fig. 4).

Pretherapy six ears showed "B"-type curve on impedance audiometry, implying OME due to tumor itself. When reassessed at the completion of therapy, 13 ears were found to have features of OME. Amongst these, five patients (ten ears) had bilateral OME. None of them progressed to chronic otitis media in the span of our study.

Radiation dose to right cochlea ranged from 0.43 to $81.6 \mathrm{~Gy}$ and to left cochlea ranged from 0.47 to $84.59 \mathrm{~Gy}$. The average doses of radiation to right and left ears, respectively were 27.10 and $24.66 \mathrm{~Gy}$. The Pearson's correlation between the dose to cochlea and hearing loss was $<0.2$, which is poor.

\section{Discussion}

Ewald in 1905 was the first to note the adverse effect of radiation on inner ear. Although his observation was made in pigeons, physicians soon noticed the same in man. ${ }^{3}$ Hearing loss due to radiation and chemotherapy for head and neck cancer adds to the morbidity of the patients. ${ }^{4}$ It can be either SNHL or conductive hearing loss (CHL) or both.

RT can cause both early and late onset SNHL. Early onset SNHL can occur during the therapy itself or shortly after its completion ${ }^{5}$ and is usually partially or completely reversible. ${ }^{6}$ Late onset SNHL occurs few months or years after therapy completion. ${ }^{7}$ It is typically chronic, progressive, and irreversible. ${ }^{8}$ This could escape the radiotherapist's knowledge as the patient may have completed follow-up before expressing this complication. Ho et al reported that SNHL after radiation was found between 1.5 and 2 years and $40 \%$ of the ears 


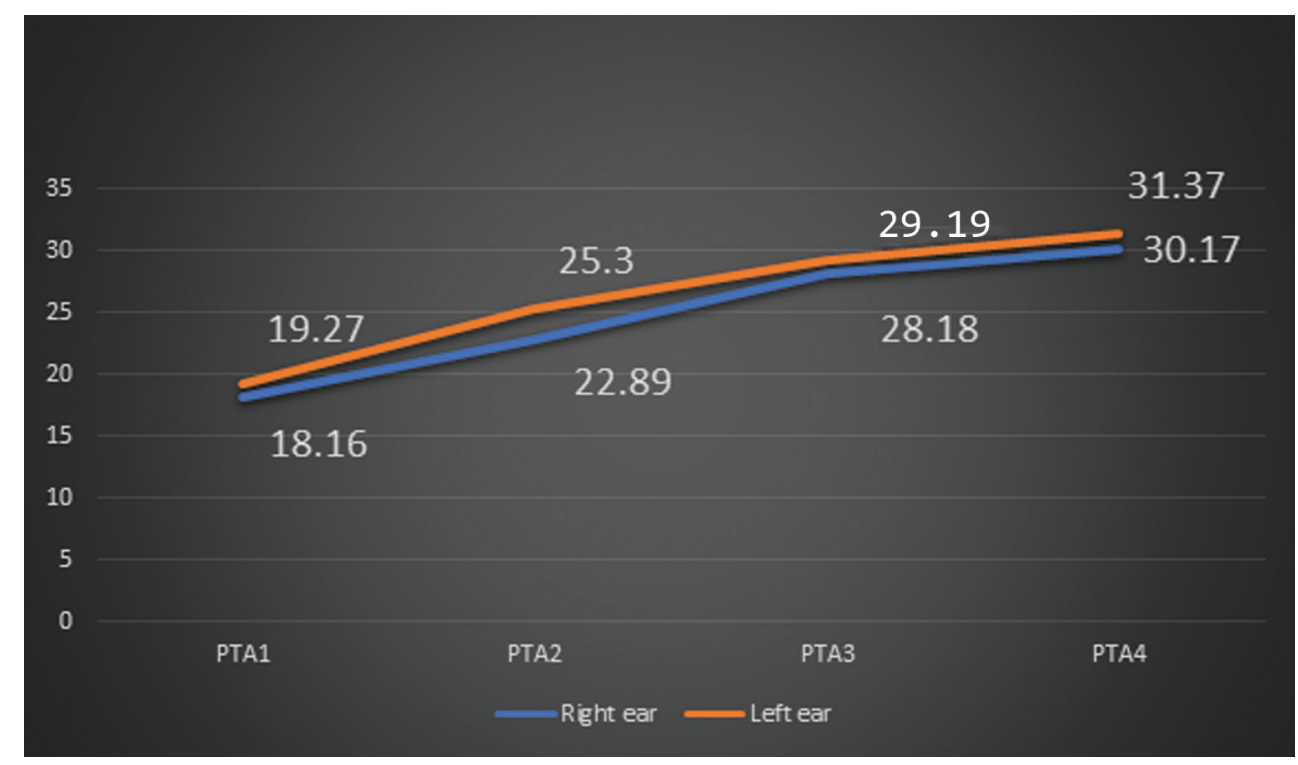

Fig. 1 Mean hearing loss in right and left ear over the time frame.

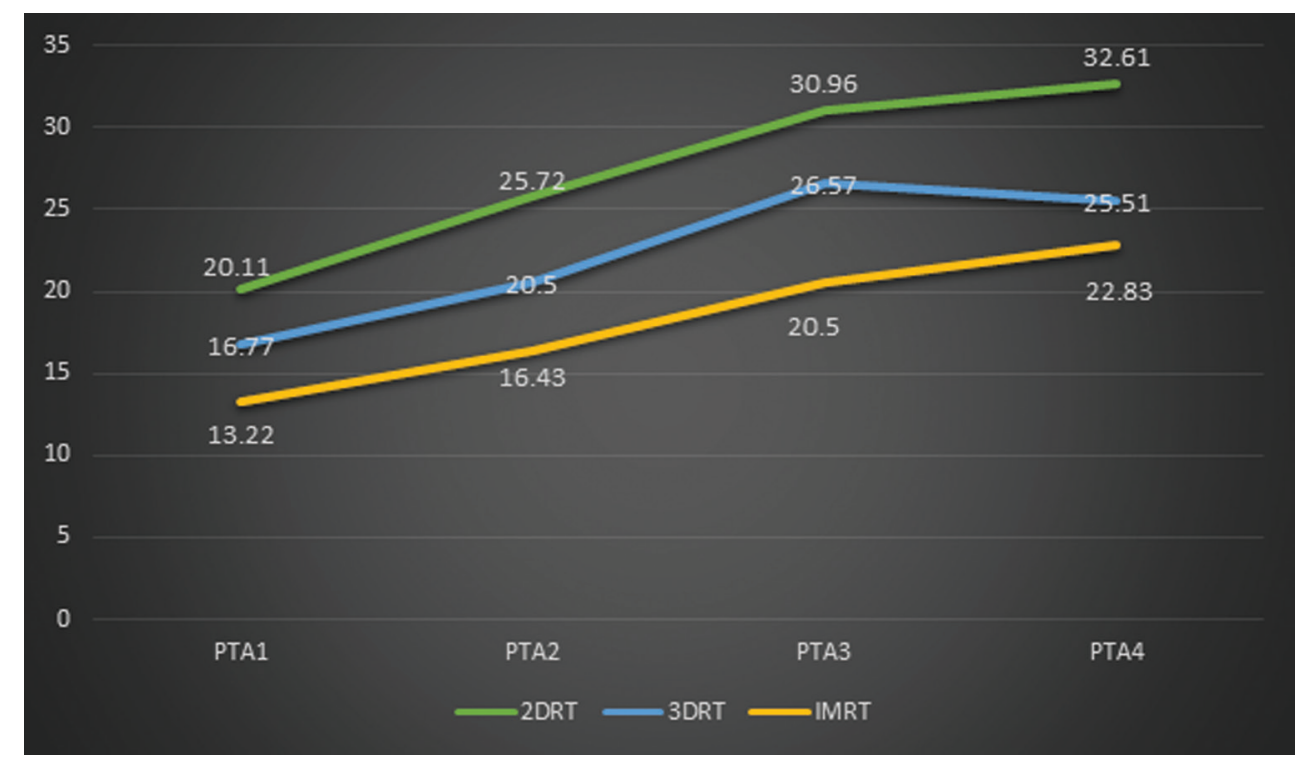

Fig. 2 Mean Hearing loss $(\mathrm{dB})$ in the right ear over the time frame amongst different types of RT. RT, radiation therapy.

recovered by 2 years. ${ }^{6}$ In a study by Bhandare et al, the mean interval between completion of RT and development of persistent SNHL was 1.8 years (range $0.5-5.9$ ). The latency time was similar for patients with dose to cochlea $<60$ and $>60 \mathrm{~Gy}$, indicating that onset of SNHL is not affected by total dose to cochlea. The latency time with once a day and twice a day fractionation was 2.1 and 1.45 years, respectively. The latency time for CTRT and only RT was 0.8 and 2 years, respectively. ${ }^{9}$ In our study, 12 (60\%) started developing SNHL mid-therapy, five (25\%) at the completion of therapy and three (15\%) 3 months post-therapy. As we did not have a longer follow-up, we cannot comment on late onset SNHL and the incidence of resolution/persistence of SNHL.

Cochlea is more sensitive to the effects of radiation than the brain and auditory nerves. ${ }^{10}$ Histopathologically, the two components of cochlea most affected are organ of Corti and stria vascularis. ${ }^{3}$ The basal turn of cochlea which is responsible for hearing in higher frequencies, ${ }^{3}$ is affected more than the apex, ${ }^{11}$ leading to predominant SNHL at higher frequency. Disruptive effects on stria vascularis lead to endolymphatic hydrops, causing ear fullness, hearing loss, tinnitus, and vertigo. Cell loss in the spiral ganglion and atrophy of nerve within the modiolus and intracanalicular cochlear nerve have been described. ${ }^{3}$

The incidence of post radiation SNHL ranges from 0 to $50 \%{ }^{6,7,12}$ In a systemic review, Raaijmakers et al showed that at least one out of three patients receiving radiation of $70 \mathrm{~Gy}$ to a primary tumor near inner ear develop hearing impairment $\geq 10 \mathrm{~dB}$ at $4 \mathrm{kHz} .^{13}$ In our study, 20 patients (50\%) developed SNHL with eight suffering from bilateral SNHL. Out of these 20 , eleven (55\%) had mild, seven (35\%) had moderate, and two (10\%) had severe grade of SNHL. 


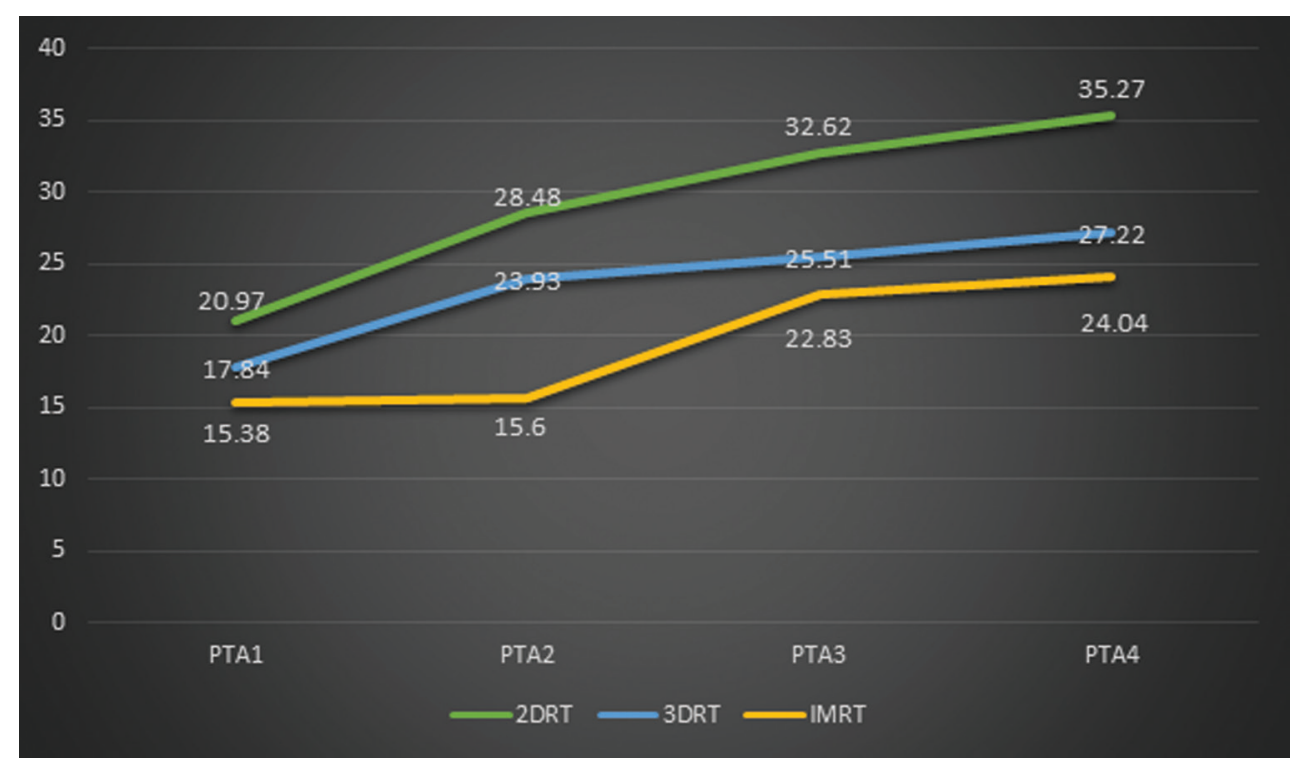

Fig. 3 Mean Hearing loss $(\mathrm{dB})$ in the left ear over the time frame amongst different types of RT. RT, radiation therapy.

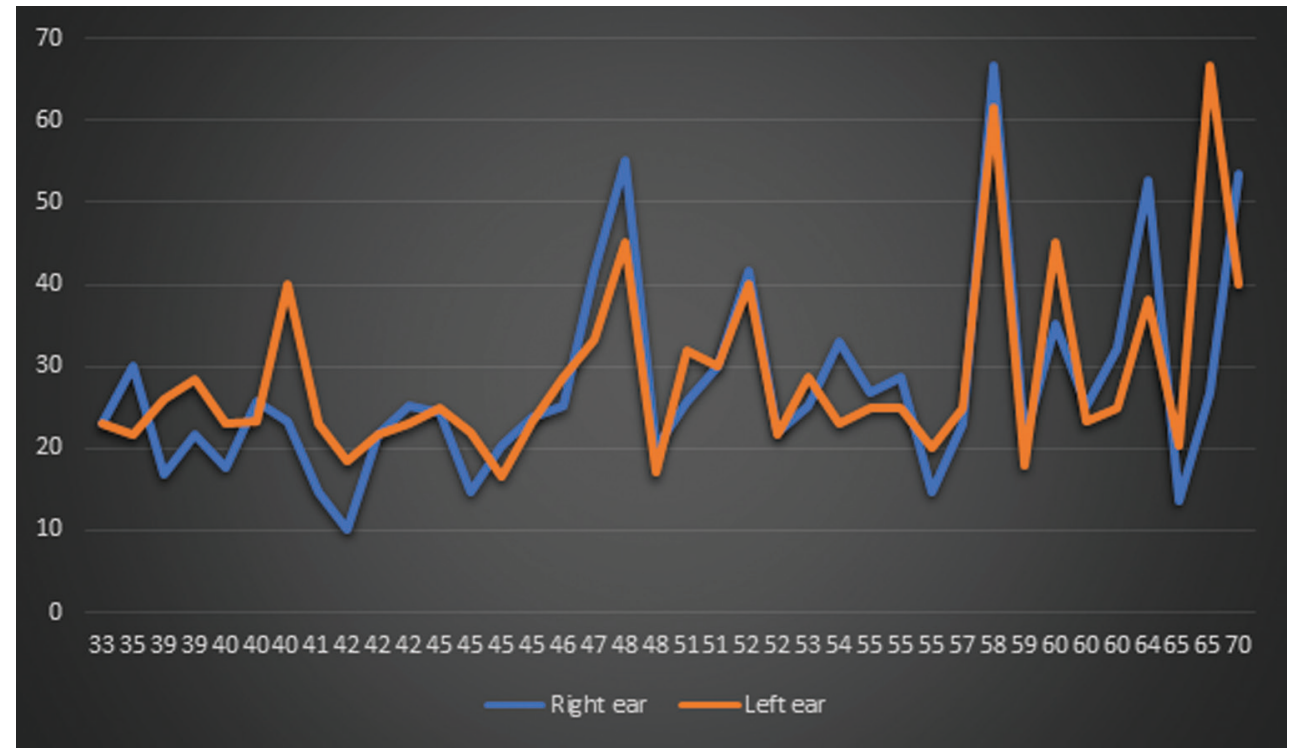

Fig. 4 Mean hearing loss (dB) post-therapy in right and left ear with increasing age.

Various factors can determine the degree of SNHL-age, tumor location, the dose of radiation to cochlea, the technique of irradiation, use of fractionated RT, and adjuvant use of chemotherapy.

Age is an important factor as deterioration of hearing is known to occur with increasing age. Studies have shown statistically significant greater hearing loss in older patients due to radiation. ${ }^{7,9,14}$ The impact on hearing acuity is seen more in higher frequency than lower. ${ }^{12,15}$ In our study, correlation between increasing age and hearing loss at the completion of therapy was done and we found greater hearing loss in older patients.

Closer the tumor to the inner ear, more will be the radiation dosage received by it and greater will be the hearing loss. Maximal studies correlating radiation and hearing loss involve patients with nasopharyngeal tumor due to its proximity to both the ET and inner ear. In our study, as most of the tumor subsites were in oropharynx and oral cavity, we did not find any significant correlation between tumor location, dose to cochlea, and hearing loss.

Pan et al found that mean dose to cochlea is a statistically significant factor in determining the incidence and degree of SNHL. In their study, a clinically significant hearing loss (>10 dB) occurred with a dose $\geq 45 \mathrm{~Gy}$. They further suggested that this SNHL occurs throughout the entire frequency range of hearing but is clinically apparent at higher frequency $>2,000$ $\mathrm{Hz}$. The upper end of speech frequency $(2,000-4,000 \mathrm{~Hz})$ is necessary for consonant sound recognition, hence hearing loss in this range can result in reduced speech recognition abilities. ${ }^{12}$ Grau et al reported 22 patients to have significant SNHL for cochlear doses $>50 \mathrm{~Gy} .{ }^{11}$ Honoré et al found that at lower frequency, no statistically significant dose-response 
relationship could be demonstrated whereas frequency $\geq 4,000 \mathrm{~Hz}$ shows a loss of $0.306 \mathrm{~dB} / \mathrm{Gy} .{ }^{16}$ Merchant et al studied 72 children treated with conformal RT and suggested that the average cochlear dose should be kept <32 Gy to prevent hearing loss. ${ }^{17}$ In our study, the average dose of radiation to right and left ears, respectively were 29.53 and $26.90 \mathrm{~Gy}$ which was well within acceptable range.

2DRT was the first radiation based on bony anatomy aimed to sufficiently irradiate the tumor. Large volumes of normal tissue were also included causing toxicities. With the introduction of computed tomography in 1970s, tumor and the surrounding organs at risk were mapped better. 3DRT was implemented in the 1980s and radiation beams now fitted the size and shape of tumor better. IMRT was introduced in mid 1990s and it uses dynamic collimators where beams of various intensities can hit at different angles. These conform more precisely to the 3D shape of the tumor with control over beam intensity, minimizing the radiation dose to organs at risk including cochlea ( - Fig. 5). ${ }^{18-20}$ Petsuksiri et al found patients who received IMRT to have lower incidence of SNHL when compared with conventional RT ( 37 vs. $48.75 \%$ at $4 \mathrm{kHz}$ ). ${ }^{21}$ A study done by Theunissen et al included 101 patients who received IMRT for various head and neck tumors and their hearing loss was compared with the normal hearing for that respective age. They concluded that hearing loss with IMRT was clinically irrelevant at both short- and long-term follow-ups. ${ }^{22}$ The tumor control rate with IMRT was found to be better than 2DRT for nasopharyngeal carcinoma in a study by Peng et al. The 5 -year control rate was $90.5 \%$ in the IMRT group and $84.7 \%$ in the 2DRT group. ${ }^{23}$ In our study, the mean hearing loss in both right and left ears were higher in patients who received 2DRT as compared with those who received 3DRT and IMRT.

Conventional fractionation radiotherapy (CFRT) is the most common radiation regime with a dose of $2 \mathrm{~Gy} /$ fraction/d, 5 days a week for 6 to 7 weeks. With better understanding of radiobiology, various other fractionation techniques such as accelerated hyperfractionation and hypofractionation RT were introduced. ${ }^{24}$ These vary in dose,

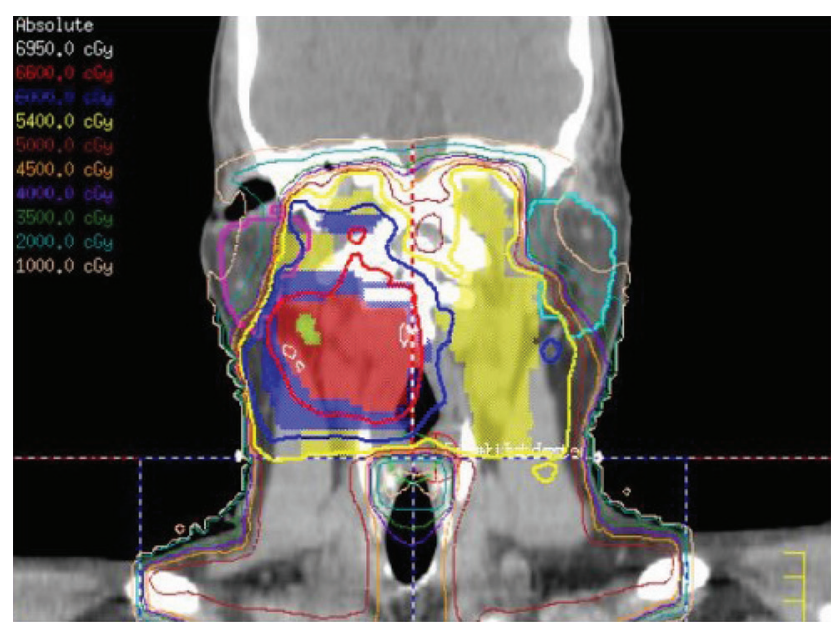

Fig. 5 Contouring in IMRT. IMRT, intensity-modulated radiotherapy. frequency, and fractions of radiation. Though they increase the overall survival rate, few studies show them to have more toxicities than CFRT. ${ }^{25}$ Whereas, trials addressing hyperfractionation reveal that they yield a moderate but consistent locoregional control of disease, with no observed increase in late toxicity. ${ }^{26}$ In our study, all our patients received treatment by CFRT.

Neoadjuvant chemotherapy has small impact on locoregional control and survival rates. ${ }^{27}$ On the contrary, concurrent CTRT yields almost 10\% higher survival rate relative to irradiation alone. Unfortunately, concurrent CTRT also has higher complication rates than those of RT only. ${ }^{28}$ Cisplatin is the most widely used chemotherapeutic drug for head and neck cancers. It causes radiosensitization in the tumor. The repairable single-strand breaks in DNA caused by radiation are converted into lethal double-strand breaks by cisplatin. Cisplatin functions as a free electron scavenger and impairs the DNA repair mechanism, thereby reduces the ability to "fix" the radiation-induced DNA damage. Radiation enhances the uptake of cisplatin into the cell and helps generate active platinum metabolites. ${ }^{28}$

Cisplatin interferes with the signal transduction from the Organ of Corti in cochlea by causing damage at three sitesouter hair cells, spiral ganglion, and stria vascularis. It also causes depletion of magnesium which is required to maintain hair cell permeability and cochlear blood flow. Magnesium deficiency also affects the ionic composition of perilymph and endolymph and lowers the threshold to stimulate a cochlear action potential. Cisplatin damages the first row of outer hair cells at the base of the cochlea resulting in bilateral high frequency SNHL. Cumulative increase in Cisplatin dose compounded with radiation causes progressive loss of hair cells apically in cochlea to involve the speech frequencies. ${ }^{10}$

In a longitudinal study, Chan et al studied SNHL after treatment of nasopharyngeal carcinoma with only radiation versus CTRT. After a 2-year follow-up, they found persistent SNHL in 40 and $56.4 \%$ of the patients in the respective groups. ${ }^{29} \mathrm{~A}$ bivariate analysis was done to evaluate the effects of cisplatin on radiation dose levels for inner ear. The patients who received high dose of cisplatin $(>600 \mathrm{mg}$ ), had higher incidence of SNHL with radiation dose of $>50 \mathrm{~Gy}(\mathrm{RR}=3.06$; 95\%). ${ }^{21}$ A study by Hitchcock et al was done to assess contribution of cisplatin to hearing loss due to radiation. It showed no significant SNHL at cochlea dose $<40 \mathrm{~Gy}$ for patients receiving only radiation. The hearing loss at $8,000 \mathrm{~Hz}$ with $10 \mathrm{~Gy}$ to cochlea and cisplatin dose of 100 and $40 \mathrm{mg} / \mathrm{m}^{2}$ was 21.5 and $9.5 \mathrm{~dB}$, respectively. Whereas with $40 \mathrm{~Gy}$ to cochlea and cisplatin of 100 and $40 \mathrm{mg} / \mathrm{m}^{2}$, hearing loss was 38.4 and $18.9 \mathrm{~dB}$, respectively. ${ }^{30}$ Wong et al compared hearing loss with CTRT versus only radiation. At $4 \mathrm{kHz}$, CTRT group had poorer hearing than only radiation group. Furthermore, lower frequencies were affected less than higher ones, highlighting high frequency hearing loss with combined therapy. ${ }^{4}$ In our study, all patients received CTRT.

Radioprotective agents which do not interfere with cancer treatment are need of the hour. Systemic and topical antioxidants can be considered but both pose challenges. Systemic drug delivery can cause toxicity and can 
interact with chemotherapeutic drug. Intratympanic route can be considered..$^{31}$ Amifostine is a radioprotector proven to prevent xerostomia. ${ }^{32}$ Its active compound diffuses into the cell where it scavenges reactive oxygen species generated by ionizing radiation. ${ }^{33}$ As it has a slower absorption in tumor cells, it can be used in cancer. The use of amifostine to reduce cisplatin-induced ototoxicity has been debatable. A study by Fouladi et al found reduced ototoxicity in patients with medulloblastoma when amifostine was give both before and during cisplatin. ${ }^{34}$ Other studies do not show any significant reduction in hearing loss with the use of amifostine. ${ }^{30,35} \mathrm{Few}$ other possible radioprotective agents like $\mathrm{N}$-Acetyl cysteine, epicatechin, are still in stages of in vitro studies. ${ }^{36,37}$

CHL can also occur due to CTRT. The ET and middle ear are deeply embedded in temporal bone. Radiation causes edema around the ET which subsequently show signs of acute middle ear inflammation. ${ }^{11}$ OME may also be associated with parapharyngeal extension of tumor and may indicate poor prognosis. ${ }^{38}$ OME due to extrinsic compression by tumor may improve after RT and those due to direct invasion of tensor palatani or cartilaginous ET may be irreversible. ${ }^{39}$ We noticed hearing improvement in one case of nasopharyngeal cancer where the pretherapy hearing loss for right and left ears was 33.3 and $43.3 \mathrm{~dB}$ and post-therapy was 11.6 and $10 \mathrm{~dB}$, respectively. Due to the presence of pretherapy hearing loss, this case was not a part of this study. Similar to other studies, Low et al found $23.8 \%$ irradiated ears to have OME. ${ }^{40}$ In our study, pretherapy 11 ears and post irradiation 48 ears showed "B"-type curve on impedance audiometry, implying pre-existing OME due to tumor itself in the former. Post irradiation, nine patients (18 ears) had bilateral OME and none of them progressed to chronic otitis media in the span of our study.

Factors influencing OME are location of tumor, pre-existing OME, radiation dose to ET, correlation with SNHL, and technique of irradiation. The tolerance dose to ET reported for acute reaction of middle ear and for chronic otitis media is 40 and 65 to $70 \mathrm{~Gy}$, respectively. ${ }^{41}$ Another study gives values below 52 and $46 \mathrm{~Gy}$, respectively. ${ }^{42}$ The morbidity of OME was worse within 1 year of completion of radiation (40\%) than 1 year after radiation (22\%). ${ }^{42}$ One study found median time of detection of post radiation OME and SNHL to be 1.4 and 2.7 years, respectively. They also found that probability of SNHL in post radiation OME (58\%) was higher than those without OME (21\%).43

Though IMRT reduces the radiation to temporal bone, the proximal part of ET is included in the radiation field. Therefore, the occurrence of post irradiation OME remains unchanged. ${ }^{44}$ OME is typically enhanced by inflammation of nasopharynx and paranasal sinuses and these are seen in patients with nasopharyngeal tumor irrespective of use of 2DRT or IMRT. Hence, even though modern RT techniques are considered preventive measures for RT-induced ototoxicities, previous studies showed no beneficial effect on the occurrence of post irradiation OME. ${ }^{45,46}$ In our study as well, there was no statistically significant difference in incidence of OME amongst the three techniques of radiation. Although placement of a middle ear ventilation tube like grommet would seem like a possible treatment for post radiation OME, it has been known to lead to persistent otorrhea and hence is to be avoided. ${ }^{47,48}$

\section{Conclusion}

Hearing loss caused by RT and chemotherapy commonly goes ignored and unaddressed. It can range from mild to severe loss and can affect both the ears thus, increasing the morbidity of the patient. Regular audiological screening can catch it at its onset and help in early use of hearing aids. Use of newer modalities of radiation where accurate delineation of components of auditory system is done, reducing radiation exposure to them, can be beneficial. A good radioprotective agent which does not compromise the therapy per se is the need of the hour.

\section{Conflict of Interest}

None declared.

\section{References}

1 Kulkarni MR. Head and neck cancer burden in India. Int J Head Neck Surg 2013;4(1):29-35

2 Olusanya BO, Davis AC, Hoffman HJ. Hearing loss grades and the International classification of functioning, disability and health. Bull World Health Organ 2019;97(10):725-728

3 Linskey ME, Johnstone PAS. Radiation tolerance of normal temporal bone structures: implications for gamma knife stereotactic radiosurgery. Int J Radiat Oncol Biol Phys 2003;57(1):196-200

4 Low WK, Toh ST, Wee J, Fook-Chong SMC, Wang DY. Sensorineural hearing loss after radiotherapy and chemoradiotherapy: a single, blinded, randomized study. J Clin Oncol 2006;24(12):1904-1909

5 Talmi YP, Finkelstein Y, Zohar Y. Postirradiation hearing loss. Audiology 1989;28(3):121-126

6 Ho WK, Wei WI, Kwong DL, et al. Long-term sensorineural hearing deficit following radiotherapy in patients suffering from nasopharyngeal carcinoma: a prospective study. Head Neck 1999;21(6):547-553

7 Kwong DLW, Wei WI, Sham JST, et al. Sensorineural hearing loss in patients treated for nasopharyngeal carcinoma: a prospective study of the effect of radiation and cisplatin treatment. Int J Radiat Oncol Biol Phys 1996;36(2):281-289

8 Grau C, Overgaard J. Postirradiation sensorineural hearing loss: a common but ignored late radiation complication. Int J Radiat Oncol Biol Phys 1996;36(2):515-517

9 Bhandare N, Antonelli PJ, Morris CG, Malayapa RS, Mendenhall WM. Ototoxicity after radiotherapy for head and neck tumors. Int J Radiat Oncol Biol Phys 2007;67(2):469-479

10 Grewal S, Merchant T, Reymond R, McInerney M, Hodge C, Shearer P. Auditory late effects of childhood cancer therapy: a report from the Children's Oncology Group. Pediatrics 2010;125(4):e938-e950

11 Grau C, Møller K, Overgaard M, Overgaard J, Elbrønd O. Sensori-neural hearing loss in patients treated with irradiation for nasopharyngeal carcinoma. Int J Radiat Oncol Biol Phys 1991;21(3):723-728

12 Pan CC, Eisbruch A, Lee JS. Snorrason RM, Ten Haken RK, Kileny PR. Prospective study of inner ear radiation dose and hearing loss in head-and-neck cancer patients. Int J Radiat Oncol Biol Phys 2005;61(5):1393-1402 
13 Raaijmakers E, Engelen AM. Is sensorineural hearing loss a possible side effect of nasopharyngeal and parotid irradiation? A systematic review of the literature. Radiother Oncol 2002;65(1):1-7

14 Zuur CL, Simis YJ, Lamers EA, et al. Risk factors for hearing loss in patients treated with intensity-modulated radiotherapy for head-and-neck tumors. Int J Radiat Oncol Biol Phys 2009;74(2):490-496

15 Herrmann F, Dörr W, Müller R, Herrmann T. A prospective study on radiation-induced changes in hearing function. Int $\mathrm{J}$ Radiat Oncol Biol Phys 2006;65(5):1338-1344

16 Honoré HB, Bentzen SM, Møller K, Grau C. Sensori-neural hearing loss after radiotherapy for nasopharyngeal carcinoma: individualized risk estimation. Radiother Oncol 2002;65(1):9-16

17 Merchant TE, Gould CJ, Xiong X, et al. Early neuro-otologic effects of three-dimensional irradiation in children with primary brain tumors. Int J Radiat Oncol Biol Phys 2004;58(4):1194-1207

18 van der Veen J, Nuyts S. Can intensity-modulated-radiotherapy reduce toxicity in head and neck squamous cell carcinoma? Cancers (Basel) 2017;9(10):E135

19 Ge X, Liao Z, Yuan J, et al. Radiotherapy-related quality of life in patients with head and neck cancers: a meta-analysis. Support Care Cancer 2020;28(6):2701-2712

20 Tribius S, Bergelt C. Intensity-modulated radiotherapy versus conventional and 3D conformal radiotherapy in patients with head and neck cancer: is there a worthwhile quality of life gain. ? Cancer Treat Rev 2011;37(7):511-519

21 Petsuksiri J, Sermsree A, Thephamongkhol K, et al. Sensorineural hearing loss after concurrent chemoradiotherapy in nasopharyngeal cancer patients. Radiat Oncol 2011;6(1):19

22 Theunissen EA, Zuur CL, Yurda ML, et al. Cochlea sparing effects of intensity modulated radiation therapy in head and neck cancers patients: a long-term follow-up study. J Otolaryngol Head Neck Surg 2014;43(1):30

23 Peng G, Wang T, Yang KY, et al. A prospective, randomized study comparing outcomes and toxicities of intensity-modulated radiotherapy vs. conventional two-dimensional radiotherapy for the treatment of nasopharyngeal carcinoma. Radiother Oncol 2012;104(3):286-293

24 Zhu B, Kou C, Bai W, et al. Accelerated hyperfractionated radiotherapy versus conventional fractionation radiotherapy for head and neck cancer: a meta-analysis of randomized controlled trials. J Oncol 2019;2019:7634746

25 Liu Y, Kou C, Bai W, et al. Altered fractionation radiotherapy with or without chemotherapy in the treatment of head and neck cancer: a network meta-analysis. OncoTargets Ther 2018;11:5465-5483

26 Foote RL, Ang KK, Head and neck tumors, overview. In: Gunderson LL, Tepper JE, eds Clinical Radiation Oncology 4th ed. Philadelphia, PA: Elsevier; 2016 561-569

27 Munro AJ. An overview of randomised controlled trials of adjuvant chemotherapy in head and neck cancer. Br J Cancer 1995;71(1):83-91

28 El-Sayed S, Nelson N. Adjuvant and adjunctive chemotherapy in the management of squamous cell carcinoma of the head and neck region. A meta-analysis of prospective and randomized trials. J Clin Oncol 1996;14(3):838-847

29 Chan SH, Ng WT, Kam KL, et al. Sensorineural hearing loss after treatment of nasopharyngeal carcinoma: a longitudinal analysis. Int J Radiat Oncol Biol Phys 2009;73(5):1335-1342

30 Hitchcock YJ, Tward JD, Szabo A, Bentz BG, Shrieve DC. Relative contributions of radiation and cisplatin-based chemotherapy to sensorineural hearing loss in head-and-neck cancer patients. Int J Radiat Oncol Biol Phys 2009;73(3):779-788

31 Mujica-Mota MA, Lehnert S, Devic S, Gasbarrino K, Daniel SJ. Mechanisms of radiation-induced sensorineural hearing loss and radioprotection. Hear Res 2014;312:60-68

32 Brizel DM, Wasserman TH, Henke M, et al. Phase III randomized trial of amifostine as a radioprotector in head and neck cancer. J Clin Oncol 2000;18(19):3339-3345

33 Hall EJ, Cox JD, Physical and biologic basis of radiation therapy. In: Cox JD, Ang KK, eds Radiation Oncology: Rationale, Technique, Results 9th ed. Philadelphia, PA: Mosby Elsevier; 2010;3-49

34 Fouladi M, Chintagumpala M, Ashley D, et al. Amifostine protects against cisplatin-induced ototoxicity in children with average-risk medulloblastoma. J Clin Oncol 2008;26(22):3749-3755

35 Paulino AC, Lobo M, Teh BS, et al. Ototoxicity after intensity-modulated radiation therapy and cisplatin-based chemotherapy in children with medulloblastoma. Int J Radiat Oncol Biol Phys 2010;78(5):1445-1450

36 Low W-K, Sun L, Tan MGK, Chua AWC, Wang D-Y. L-NAcetylcysteine protects against radiation-induced apoptosis in a cochlear cell line. Acta Otolaryngol 2008;128(4):440-445

37 Pyun JH, Kang SU, Hwang HS, et al. Epicatechin inhibits radiation-induced auditory cell death by suppression of reactive oxygen species generation. Neuroscience 2011;199:410-420

38 Lau SK, Wei WI, Sham J, Hui Y, Choy D. Effect of irradiation on middle ear effusion due to nasopharyngeal carcinoma. Clin Otolaryngol Allied Sci 1992;17(3):246-250

39 Kew J, King AD, Leung SF, et al. Middle ear effusions after radiotherapy: correlation with pre-radiotherapy nasopharyngeal tumor patterns. Am J Otol 2000;21(6):782-785

40 Low WK, Fong KW. Long-term hearing status after radiotherapy for nasopharyngeal carcinoma. Auris Nasus Larynx 1998;25(1):21-24

41 Emami B, Lyman J, Brown A, et al. Tolerance of normal tissue to therapeutic irradiation. Int J Radiat Oncol Biol Phys 1991;21(1):109-122

42 Wang SZ, Wang WF, Zhang HY, Guo M, Hoffman MR, Jiang JJ. Analysis of anatomical factors controlling the morbidity of radiation-induced otitis media with effusion. Radiother Oncol 2007;85(3):463-468

43 Bhandare N, Moisseenko V, Song WY, Morris CG, Antonelli P, Mendenhall WM. Evaluating the association between pre- and postradiation therapy otitis media with effusion and the incidence of sensory-neural hearing loss in head-and-neck cancer patients. Int J Radiat Oncol 2012;84(3):S515-S516

44 Kujawski OB, Poe DS. Laser eustachian tuboplasty. Otol Neurotol 2004;25(1):1-

$45 \mathrm{Hsin} \mathrm{CH}$, Chen TH, Liang KL, Tseng HC, Liu WS. Postirradiation otitis media with effusion in nasopharyngeal carcinoma patients treated by intensity-modulated radiotherapy. Laryngoscope 2013;123(9):2148-2153

46 Hsin C-H, Chen T-H, Young Y-H, Liu W-S. Comparison of otologic complications between intensity-modulated and two-dimensional radiotherapies in nasopharyngeal carcinoma patients. Otolaryngol Head Neck Surg 2010;143(5):662-668

47 Skinner DW, van Hasselt CA. A study of the complications of grommet insertion for secretory otitis media in the presence of nasopharyngeal carcinoma. Clin Otolaryngol Allied Sci 1991;16(5):480-482

48 Chen CY, Young YH, Hsu WC, Hsu MM. Failure of grommet insertion in post-irradiation otitis media with effusion. Ann Otol Rhinol Laryngol 2001;110(8):746-748 